\title{
ERRATUM
}

\section{Erratum to: Thymic squamous cell carcinoma producing granulocyte colony-stimulating factor associated with a high serum level of interleukin 6}

Eriko Ayabe $\cdot$ Kyoichi Kaira $\cdot$ Toshiaki Takahashi $\cdot$ Haruyasu Murakami Asuka Tsuya • Yukiko Nakamura · Tateaki Naito • Masahiro Endo • Nobuyuki Yamamoto

Published online: 22 January 2010

(C) Japan Society of Clinical Oncology 2010

Erratum to: Int J Clin Oncol (2009) 14:534-536

DOI 10.1007/s10147-009-0875-6

In the printed version of the article, the accepted date was incorrectly shown. The correct date should be January 10, 2009, not 2008.

The publisher sincerely apologizes for the error.

The online version of the original article can be found under doi:10.1007/s10147-009-0875-6.

E. Ayabe · K. Kaira ( $₫) \cdot$ T. Takahashi · H. Murakami ·

A. Tsuya $\cdot$ Y. Nakamura $\cdot$ T. Naito $\cdot$ N. Yamamoto

Division of Thoracic Oncology, Shizuoka Cancer Center,

1007 Shimonagakubo Nagaizumi-cho,

Shizuoka 411-8777, Japan

e-mail: kkaira1970@yahoo.co.jp

M. Endo

Division of Diagnostic Radiology,

Shizuoka Cancer Center, Shizuoka, Japan 